\title{
Design and Energy Analysis of a Solar Desiccant Evaporative Cooling System with Built-In Daily Energy Storage
}

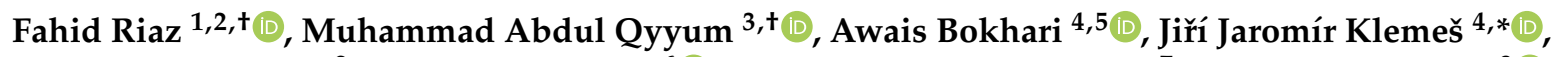 \\ Muhammad Usman ${ }^{2}$, Muhammad Asim 6 ${ }^{6}$, Muhammad Rizwan Awan ${ }^{7}$, Muhammad Imran ${ }^{8} \mathbb{D}$ and \\ Moonyong Lee ${ }^{3}$ (i)
}

1 Department of Mechanical Engineering, National University of Singapore, Singapore 117575, Singapore; fahid.riaz@u.nus.edu

2 Department of Mechanical Engineering, University of Engineering and Technology Lahore, Lahore 54000, Pakistan; muhammadusman@uet.edu.pk

3 School of Chemical Engineering, Yeungnam University, Gyeongsan 712-749, Korea; maqyyum@yu.ac.kr (M.A.Q.); mynlee@yu.ac.kr (M.L.)

4 Sustainable Process Integration Laboratory-SPIL, NETME Centre, Faculty of Mechanical Engineering, Brno University of Technology-VUT Brno, Technická 2896/2, 61669 Brno, Czech Republic; bokhari@fme.vutbr.cz

5 Department of Chemical Engineering, COMSATS University Islamabad (CUI), Lahore Campus, Punjab 54000, Pakistan

6 Research Centre for Green Energy, Transport and Building (RCGETB), School of Professional Education and Executive Development, College of Professional \& Continuing Education,

The Hong Kong Polytechnic University, Kowloon 100077, Hong Kong; muhammad.asim@cpce-polyu.edu.hk

7 Department of Mechanical, Hydraulics and Aeronautics, Universitat Politechnicia De Catalunya (UPC), 08800 Barcelona, Spain; mrawan@kth.se

check for

updates

Citation: Riaz, F.; Qyyum, M.A.; Bokhari, A.; Klemeš, J.J.; Usman, M.; Asim, M.; Awan, M.R.; Imran, M.; Lee, M. Design and Energy Analysis of a Solar Desiccant Evaporative Cooling System with Built-In Daily Energy Storage. Energies 2021, 14, 2429. https://doi.org/10.3390/en14092429

Academic Editor: Antonio Rosato

Received: 26 March 2021

Accepted: 20 April 2021

Published: 24 April 2021

Publisher's Note: MDPI stays neutral with regard to jurisdictional claims in published maps and institutional affiliations.

Copyright: (c) 2021 by the authors. Licensee MDPI, Basel, Switzerland. This article is an open access article distributed under the terms and conditions of the Creative Commons Attribution (CC BY) license (https:/ / creativecommons.org/licenses/by/ $4.0 /)$.
8 School of Mechanical, Biomedical and Design Engineering, College of Engineering and Applied Sciences, Aston University, Aston Triangle, Birmingham B4 7ET, UK; m.imran12@aston.ac.uk

* Correspondence: jiri.klemes@vutbr.cz

+ These authors contributed equally.

Abstract: Heat storage with thermochemical (TC) materials is a promising technology for solar energy storage. In this paper, a solar-driven desiccant evaporative cooling (DEC) system for air-conditioning is proposed, which converts solar heat energy into cooling with built-in daily storage. The system utilises thermochemical heat storage along with the DEC technology in a unique way. Magnesium Chloride $\left(\mathrm{MgCl}_{2} \cdot 6 \mathrm{H}_{2} \mathrm{O}\right)$ has been used, which serves as both a desiccant and a thermochemical heat storage medium. The system has been designed for the subtropical climate of Lahore, Pakistan, for a bedroom with $8 \mathrm{~h}$ of cooling requirements during the night. MATLAB has been employed for modelling the system. The simulation results show that $57 \mathrm{~kg}$ of magnesium chloride is sufficient to meet $98.8 \%$ of cooling demand for the entire month of July at an elevated cooling requirement. It was found that the cooling output of the system increased with increasing heat exchanger effectiveness. The heat exchangers' effectiveness was increased from 0.7 to 0.8 , with the solar fraction increased from $70.4 \%$ to $82.44 \%$. The cooled air supplied to the building meets the fresh air requirements for proper ventilation.

Keywords: desiccant; evaporative; cooling; air conditioning; solar; energy storage; refrigeration

\section{Introduction}

Buildings are consuming about $40 \%$ of global primary energy and account for around $33 \%$ of the world's carbon dioxide $\left(\mathrm{CO}_{2}\right)$ emissions [1]. Vapour compression cycle (VCC) is the most commonly used refrigeration technology all over the world [2]. Rapid urbanisation and an increase in the quality of life has been increasing the global cooling demand. According to the UN, by 2050, about $70 \%$ of the world's population will be living in cities [3], and the world's cooling demand is expected to triple by 2050 [4]. Approximately 
up to half of the energy input to industries is released to the environment by stacks and flare gases as low-temperature heat [5]. Low-temperature heat is also available in abundance from green sources such as geothermal energy [6] and solar thermal energy [7]. Low-temperature heat utilisation can lead to increased energy efficiency, which is a key parameter to energy transition goals [8] and low-grade heat-driven refrigeration systems present a great solution to meet the challenge of a rapid increase in air-conditioning demand [9], especially for tropical areas, for which harnessing low-grade heat is more challenging [10]. Solar energy is considered as an alternative to fossils for refrigeration because of its coincidence of availability, cooling demand, and severe water scarcity [11]. Desiccant evaporative cooling (DEC) systems are heat-driven systems used as an alternative to conventional vapour compression systems [12]. The system can be operated in open (more common) or closed-cycle modes [13]. A heat source is required for the regeneration of the desiccant, and low-temperature heat (at 60-90 ${ }^{\circ} \mathrm{C}$ ) may be utilised [14]. In DEC, heat is used to dry desiccant (hygroscopic) material, and the dry material is used to produce dry air by absorbing water vapour from it. Water is then evaporated in this dry air in the next stage to produce cooling due to evaporation. DEC is a promising low-energy cooling technology as the moisture (latent cooling load) from humid air is removed by utilising the chemical affinity between desiccant material and water. It cannot be removed by reducing the temperature below the dew point. DEC systems are naturally suitable for applications with higher ventilation requirements. A DEC system can use both solid sorption materials or liquid sorption materials. Commercially available desiccants are silica gel, natural and synthetic zeolites, activated alumina, lithium chloride, and synthetic polymers [15]. DEC technology decouples the latent and sensible cooling loads by making it possible to condition spaces with a wide range of design conditions [16]. The open DEC cycles produce conditioned air directly, whereas closed cycles are mostly used to produce chilled water. Most of the standard open cycles use a rotating desiccant wheel combined with a silica gel or lithium-chloride solution as a sorption material [17]. Desiccant dehumidifiers are used along with air conditioning systems to remove the latent load (water vapour) from the air before it enters the air conditioning system. These are used in commercial buildings where integrated heating, ventilation, and air conditioning (HVAC) systems are installed [18]. Several theoretical and experimental studies have been conducted on DEC systems. Fatouh et al. [19] did an experimental investigation for the characterisation of a cooling system comprising of a vapour compression system integrated with activated alumina with multiple layers. The systems were investigated under humid tropical conditions (relative humidity of 50-80\%) with a fresh air ratio in the range of 40-100\%. Finocchiaro et al. [20] investigated a compact DEC system named "Freescoo" (free solar cooling). The system involves a photovoltaic-thermal system and is suitable for a small-scale built environment. The power consumption of the system is about $5 \%$ of the conventional system. Ham et al. [21] developed a liquid-desiccant, evaporative (in-direct, dewpoint) cooling system. Simulation results showed that the system saved about $12 \%$ of primary energy compared to a conventional system, while $100 \%$ fresh outdoor air was used. Shanghai Jiao combined a desiccant coated heat exchanger and a regenerative evaporative cooler and named the system SCDHE (self-cooled evaporative cooling systems). The simulation results showed that the system produced $30 \%$ more cooling as compared to the usual DCHE system [22]. La et al. [23] did experimental studies on an innovative chiller that had an open and rotary type desiccant cooling system. The results showed positive results for low-temperature heat utilisation for producing air conditioning with the supply of chilled water with temperatures of $15-20{ }^{\circ} \mathrm{C}$ and a thermal COP of $0.3-0.6$ range with respect to the chilled water production. Hourani et al. [24] studied a hybrid cooling system where an experimental setup was incorporated with a solid desiccant system and a two-stage evaporative cooling system. Compared with a single-stage evaporative cooling system, a two-stage system resulted in $16.15 \%$ less consumption of energy and $26.93 \%$ lesser consumption of water. Beccali et al. [25] evaluated the energy performance of a desiccant cooling system and designed an air handling unit for ventilation with a radiant 
ceiling to provide cooling and heating to space. The experimental set up consisted of an air handling unit for ventilation combined with the radiant ceiling fan for sensible cooling or heat energy. Flat-plate collectors are installed to provide some of the regeneration heat of the desiccant wheel in summer and for space heating in winter. The results obtained from daily and monthly monitoring in five summer months and three winter months indicate that in comparison to conventional air handling unit, primary energy savings are almost $50 \%$, and the DEC process covers the approximately $50 \%$ energy supplied by the air handling unit (AHU). Rafique et al. [26] established a mathematical model for the evaporative desiccant cooling and analyses how the device is feasible under Dhahrano, Saudi Arabia's climate conditions.

Although there are many studies reported in the literature related to the DEC systems, there is still a literature gap with respect to a system that could utilise low-grade solar thermal energy to power a DEC, which also acts as daily storage at the same time. In this paper, a novel system has been proposed, which uniquely utilises DEC technology and has been designed in such a way that the desiccant material $\left(\mathrm{MgCl}_{2} \cdot 6 \mathrm{H}_{2} \mathrm{O}\right)$ serves two purposes simultaneously, that is, it works as a desiccant (for DEC) and as a daily solar heat storage medium. The system has been designed to produce solar cooling for a small building situated in the subtropical city of Lahore, Pakistan. The system has been simulated with MATLAB by incorporating weather data of Lahore with the system modelling equations. The desiccant reactor has been modelled by developing an analytical solution to governing equations by assuming constant reactor bed temperature segments. The reactor transient model undergoes heat and mass transfer simultaneously. The solar DEC model has been incorporated with the conditioned space (bedroom), and the solar fraction is calculated. Sensitivity analysis of the various parameters has been performed too. The system has been designed to provide night cooling only, and the sizing of the collector and desiccant reactor has been performed accordingly. However, this is not a limitation of the system as the system can be made to operate continuously by increasing (3-4 times) the sizing of the collector and energy-storing reactor. The limiting factors in this regard are the availability of space for bigger collectors and reactors in residential buildings.

\subsection{System Design and Description}

The basic idea is to design a desiccant evaporative cooling system for providing cooling to a building. There should be a reactor that holds the sorption material and allows the removal of moisture from the air passing through the reactor to make it dry. During the hydration of sorption material, the heat of absorption is released and removed from the air. An evaporator is needed to evaporate water in the dry air to cool it down. A fan is needed to force the air to flow through the reactor and evaporator before entering the room. Figure 1 shows a schematic DEC process.

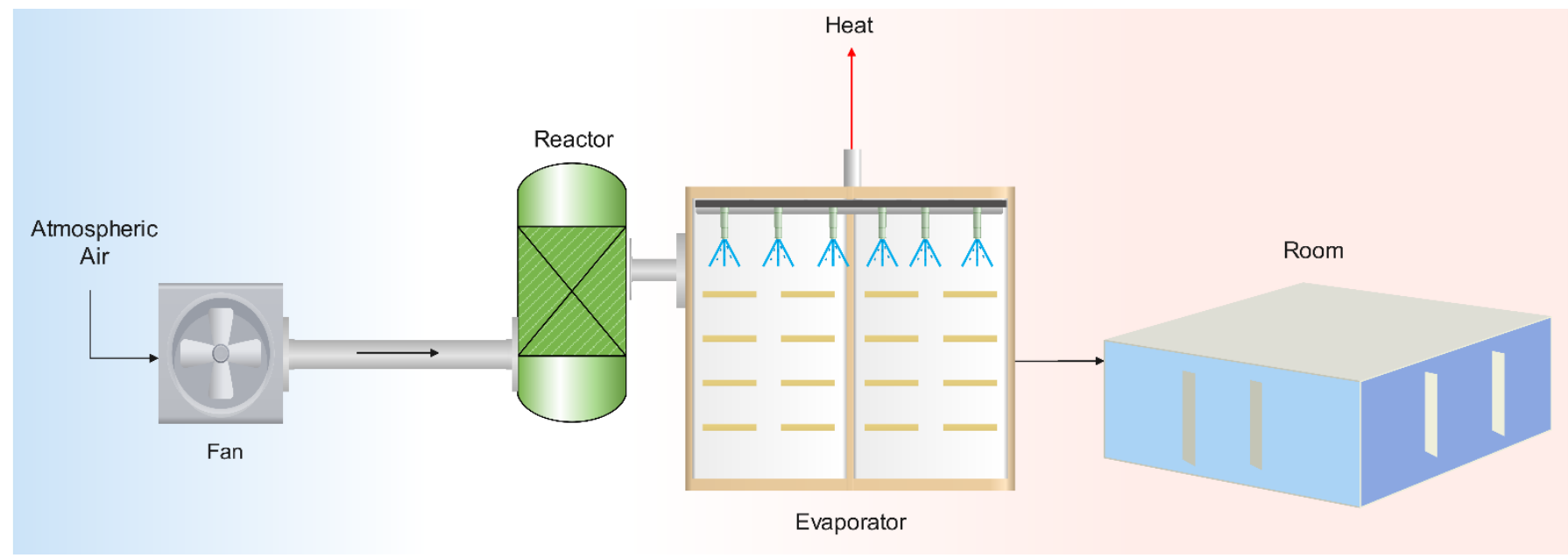

Figure 1. Schematic basic DEC concept. 
The reactor should increase the air temperature and bring the absolute humidity down by absorbing the moisture from it. The heat exchanger should bring the temperature down for the same value of absolute humidity. The evaporator should increase the absolute humidity and bring the temperature down. The increase and decrease of air temperature and moisture content are conceptually shown on a Psychrometric chart in Figure 2.

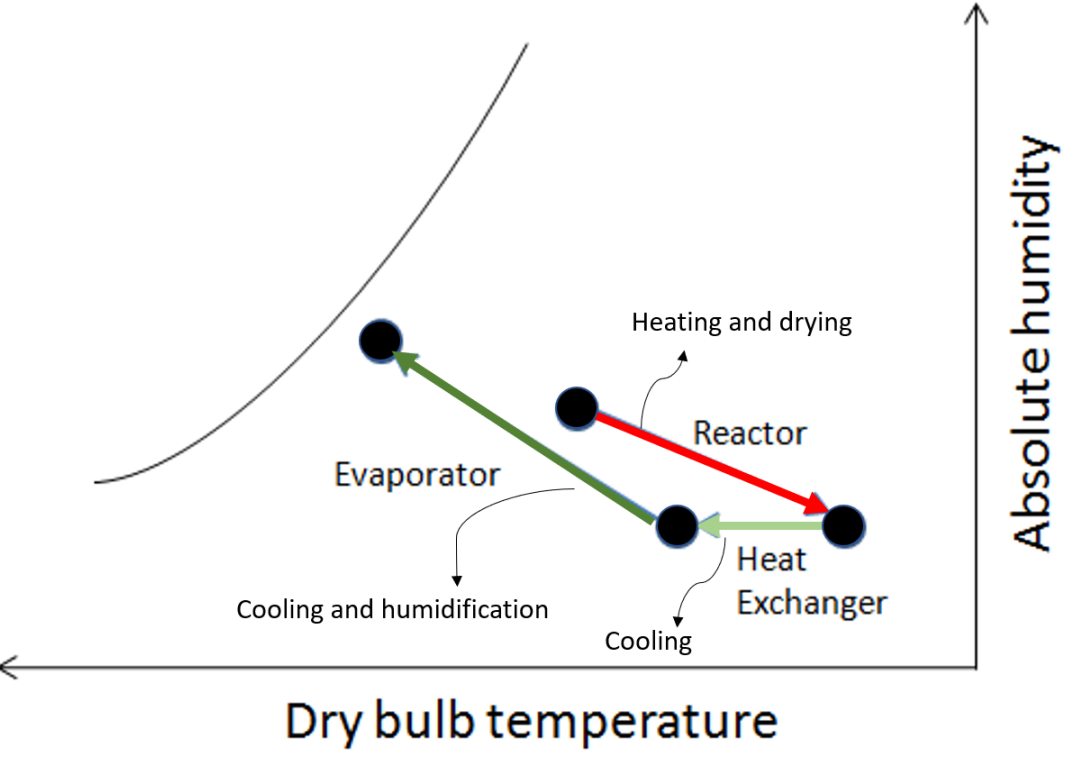

Figure 2. Conceptual variation of psychrometric air properties in a basic DEC system.

The evaporation process is a constant enthalpy process in which the heat of evaporation is absorbed from the air. The evaporation process should follow the constant enthalpy line on the psychrometric chart.

The sorption (desiccant) material needs to be charged (dried) after some time. It has a limited capacity to absorb moisture. For charging, it needs to be heated up to the dehydration temperature of the sorption material. The material should be dehydrated by passing hot air through it. Heat energy is required to heat the air to the dehydration temperature. The heating of the air is achieved by using the abundantly available solar energy in the daytime. The air is passed through a solar collector, which absorbs solar radiation and converts it into heat by transferring it to the passing through the air. For this specific case, cooling is required at night, and solar energy is available during the day. It means that the charging and discharging of the sorption material is not simultaneous. This allows using a single fan in combination with valves. The valves can be opened and closed for day and night operation, as shown in Figure 3.

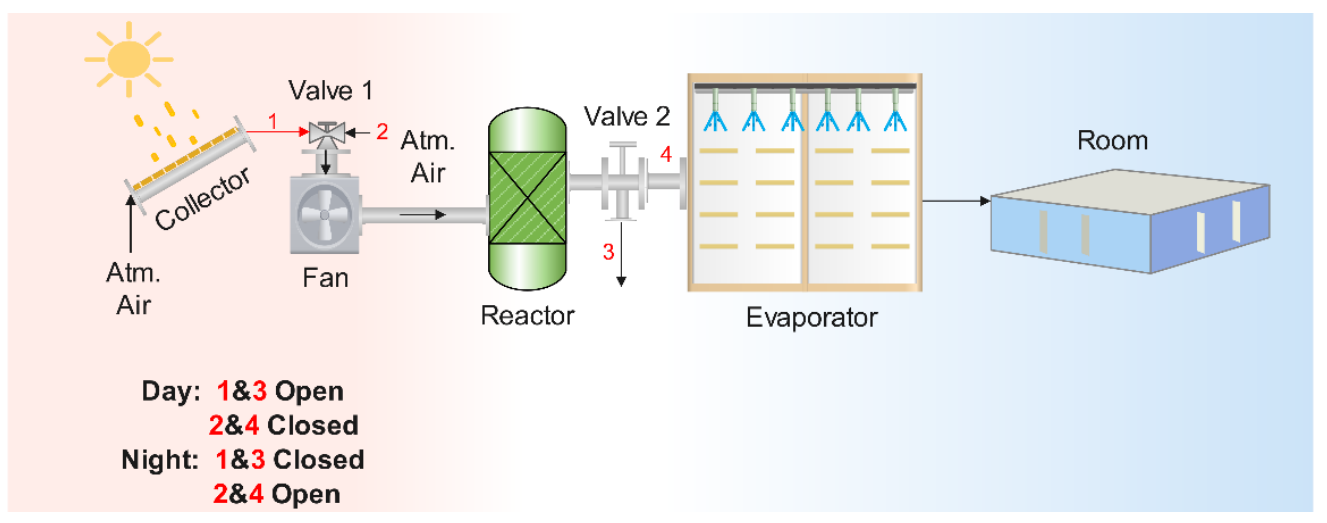

Figure 3. Day and night operation of the DEC system. 
Two-way valves are used, and the ports are numbered and shown in the red colour in Figure 3. During the daytime, the fan inducts the atmospheric air through the solar collector and the high-temperature air is delivered to the reactor for the dehydration of the sorption material. During the daytime, port 2 of valve 1 is closed. No air is inducted through this port. Similarly, as port 4 of valve 2 is closed during the daytime, there is no air delivered to the room, and the wet air is exhausted in the atmosphere. During the night, the fan inducts the atmospheric air through port 2 of valve 1 and delivers it to the reactor. The reactor dries the air and delivers it to the evaporator through port 4 of valve 2 as port 3 is closed in the night operation. The temperature and humidity of the air delivered to the room by the DEC system can be changed based on the room's requirements. Different kinds of configurations can be designed in this regard. The air coming out of the reactor is hot and dry. It can be pre-cooled by exchanging heat with the room's exhaust air at a lower temperature. This increases the initial cost of the system in spite of increasing the efficiency of the system. Another heat exchanger can be installed to exchange the heat with atmospheric air, which is at a lower temperature than the air coming out of the reactor. Figure 4 explains the installation of the heat exchangers to increase the efficiency of the system.

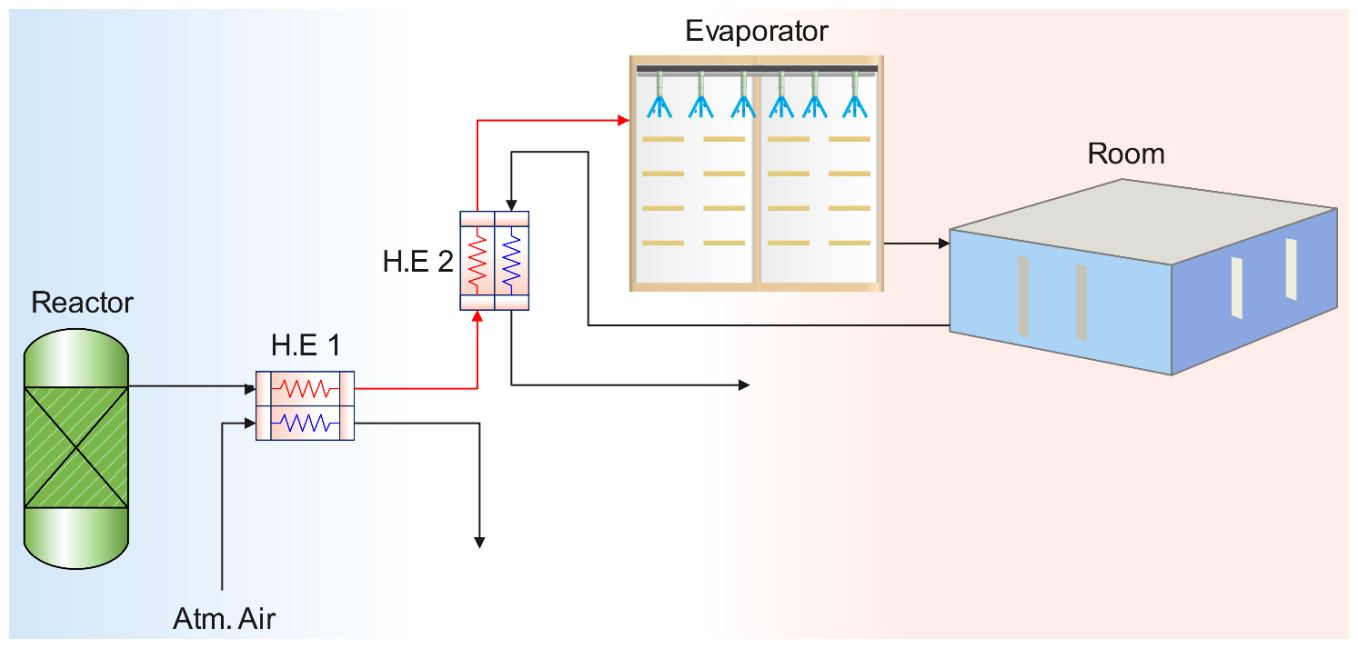

Figure 4. Schematic heat exchangers installation in DEC System.

Heat exchanger 1 (HE 1) brings the temperature down near the atmospheric temperature by increasing relative humidity. Heat exchanger 2 (HE 2) brings the temperature further down as the air coming out of the room is cooler, so the relative humidity goes further up. The extent of heat transfer in the heat exchangers depends on the type and size of the heat exchangers, which are normally limited by the heat exchangers' cost. Expensive and bigger heat exchangers provide higher effectiveness.

The air coming out of the room can be passed by another evaporator to decrease its temperature further before exchanging the heat in HE 2 to increase the system's performance further. For example, if the air coming out of the room has a temperature of $26^{\circ} \mathrm{C}$ and the relative humidity of $60 \%$, then its temperature can be reduced up to $22{ }^{\circ} \mathrm{C}$ if the evaporator increases the relative humidity up to $90 \%$ (following the constant enthalpy line on the psychrometric chart). The schematic of this evaporator is shown in Figure 5. The Evaporator 2 is typically always used in the continuous wheel type systems because it allows utilising the maximum potential of the room exhaust (return) air to increase the whole system's efficiency. If the DEC system cannot provide enough cooling to meet the cooling demand of the room or in case of high fluctuations of the room's cooling demand, the DEC system can be integrated with an auxiliary cooling system that provides additional cooling to meet the cooling demand. 


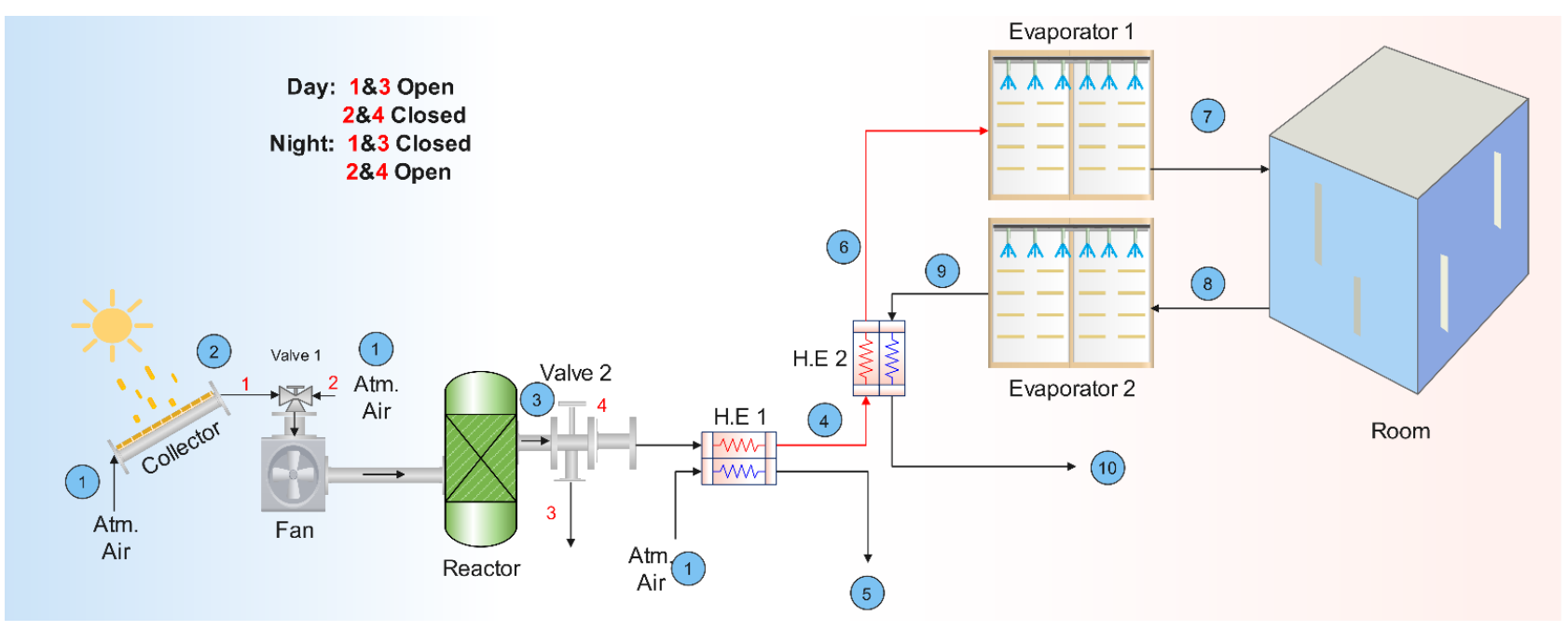

Figure 5. Final solar DEC System configuration.

\subsection{Final Design of Solar DEC System}

For the final system design, the calculations were made to select and size different components for the specific case of producing cooling in the nighttime to a small room located in Lahore. The final system, which is to be modelled for simulations, is shown in Figure 5.

This is not a continuous system as the cooling is produced during the night only. Thus, the reactor is not the wheel type that is generally used in DEC systems. The starting point for sizing components for system integration is the ventilation requirements of the room. The DEC system mass flow rate will come from the ventilation requirements of the system. During the charging of the reactor in the daytime, the incoming ambient air can be preheated by the air leaving the reactor. In this way, the wasted heat energy of the exhaust air can be utilised to increase the efficiency of the system. It will allow the use of a smaller solar collector to achieve the same performance. For simplification of the model, this option is not considered at the present stage, but it is recommended to be used in future developments to bring down the initial cost of the system. The by-pass connection for Evaporator 1 is not considered in the final system design. The calculations were made for the humidity balance of the room, and it was found that the humidity of the room does not increase above the comfortable limit. Table 1 shows that the psychrometric air properties are changing as the air passes through different components:

Table 1. Psychrometric values of different states of air in the system.

\begin{tabular}{cccc}
\hline State & Explanation & $\begin{array}{c}\text { Temp. } \\
\left({ }^{\circ} \mathbf{C}\right)\end{array}$ & $\begin{array}{c}\text { RH } \\
\mathbf{( \% )}\end{array}$ \\
\hline $\mathbf{1}$ & Night operation & & 70 \\
$\mathbf{3}$ & Reactor outlet & 33 & 10 \\
$\mathbf{4}$ & Supply after HE1 & 50 & 19 \\
$\mathbf{5}$ & Hot air after HE.1 & 38.1 & 23 \\
$\mathbf{6}$ & Supply after HE 2 & 44.9 & 35 \\
$\mathbf{7}$ & Supply air & 26.83 & 90 \\
$\mathbf{8}$ & Return air & 17 & 60 \\
$\mathbf{9}$ & Return air after & 26 & 90 \\
$\mathbf{1 0}$ & evaporator 2 & 22 & 50 \\
$\mathbf{1}$ & Return after HE 2 & 33.2 & 50 \\
$\mathbf{2}$ & Atmospheric air & 38 & 7 \\
\hline
\end{tabular}


The states ( 1 to 10$)$ mentioned in Table 1 are also indicated in Figure 5 . The values presented are conceptual values to explain the process, which is happening inside every component of the system. These are not actual values from simulation results. State 1 is the atmospheric air, and these are the typical values for day and night in July in Lahore. In the daytime, the temperature is higher, but at the nighttime, as the temperature drops, the humidity increases. For actual simulation, these values will be taken from the weather data file.

State 2 is the solar collector output and depends on the size and the type of the collector and the solar energy available on the collector. The solar collector adds heat to the air, so the temperature increases, decreasing the relative humidity as the moisture content is the same. State 3 is the outlet of the reactor. In the daytime, the reactor material is dried, the heat is absorbed in the reactor to allow the release of the water molecules, and the temperature at state 3 stays at the dehydration temperature $\left(70^{\circ} \mathrm{C}\right)$ until all the material is dehydrated. Due to the release of the water molecules by the sorption material, the air's relative humidity increases. During the night, the reactor absorbs moisture from the outside air, bringing its humidity down, and as the heat of absorption, the reaction is released, so the temperature increases. This dry and hot air, state 3, exchanges heat with atmospheric air in HE 1 to reduce the temperature and increase the relative humidity at state 4 as no moisture is added or removed. These processes are shown on the psychrometric chart in Figure 6.

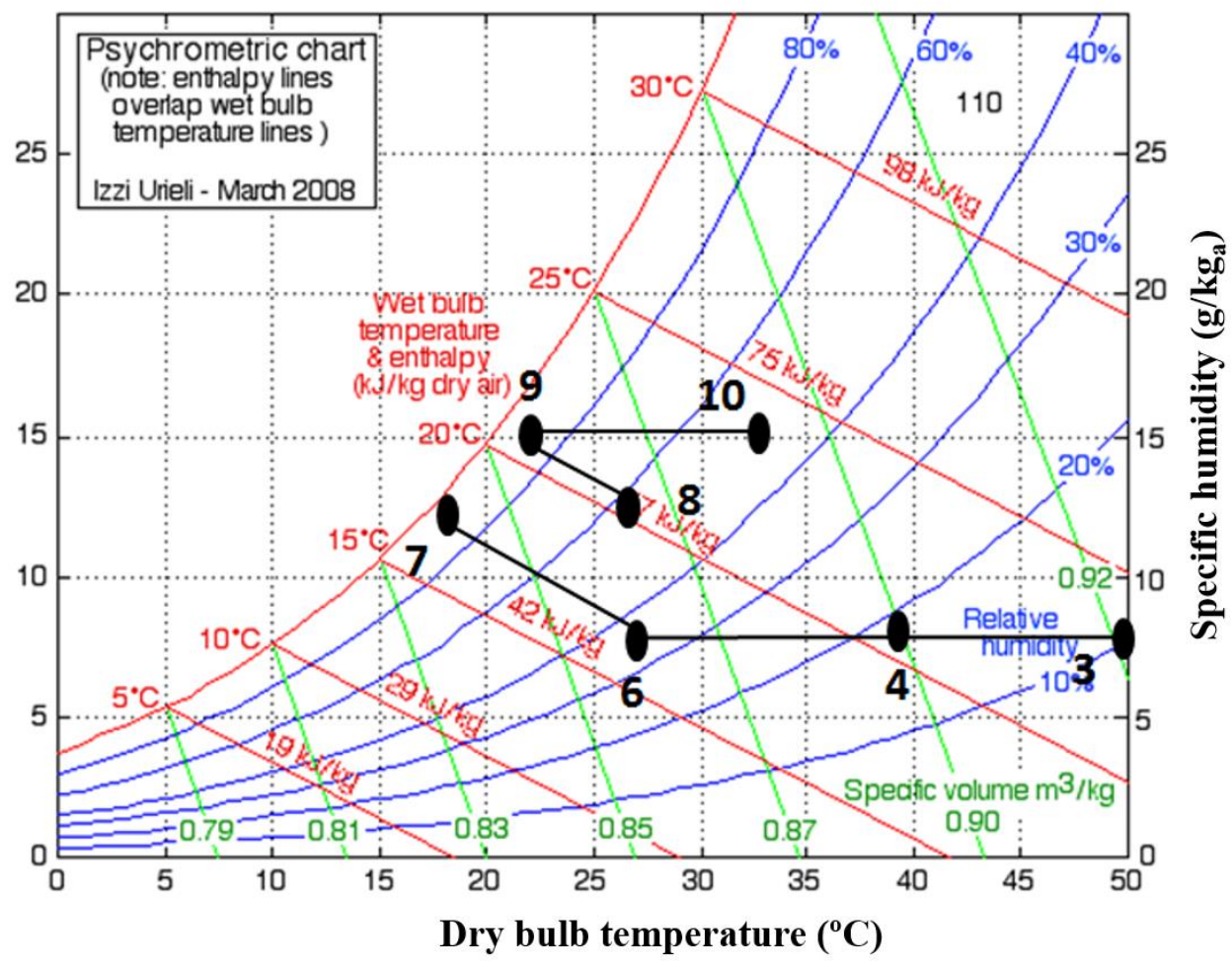

Figure 6. Psychrometric properties of air (at $1 \mathrm{~atm}$ total pressure) at different states of the system [27].

The horizontal line from 3 to 4 indicates constant absolute humidity. Similarly, from 4 to 6 , there is no change in absolute humidity. When the temperature is reducing, the relative humidity is increasing. From 6 to 7 , evaporation is taking place, so the temperature is reducing, and absolute as well as relative humidity is increasing along the constant enthalpy line. The air with state 7 is entering the room, and 8 is the state of the air coming out of the room, which is also the inside room conditions. There is heat gain inside the room, and some moisture addition visible. The process from state 8 to 9 is the evaporation process again along with the constant enthalpy to reduce temperature. From 9 to 10, there is 
a heat exchange process with constant absolute humidity. This analysis so far is indicating encouraging results for the designed system.

\section{Modelling}

\subsection{Solar Collector}

Referring to the system's schematic diagram, the temperature of the heating air should be more than the dehydration temperature of the desiccant material. Due to the hightemperature requirement, the evacuated tube collector is used in the system. The efficiency of the collector depends on the heat loss, which is a function of the difference between the mean temperature of the reactor and the ambient temperature. The efficiency of the collector $(\eta)$ is calculated by the following Equation (1).

$$
\eta=\eta_{\text {opt }}-k_{1} \frac{\left(T_{\text {mean }}-T_{a m b}\right)}{G}-k_{2} \frac{\left(T_{\text {mean }}-T_{a m b}\right)^{2}}{G}
$$

Here, $\eta_{\text {opt }}$ is the optical efficiency of the collector, and $k_{1}$ and $k_{2}$ are constant heat loss coefficients, the suitable values of which can be obtained from literature or provided by the manufacturer [28]. $G$ is the global (direct and diffused) solar irradiance on the surface of the collector in $\mathrm{W} / \mathrm{m}^{2}$, and $T_{\text {mean }}$ is the average or the mean temperature of the collector. The heat absorbed $(E)$ by the collector is given by Equation (2):

$$
E=\eta \times G \times A_{c}
$$

This heat is taken up by the air passing through the collector. Its temperature at the exit of the collector for each time interval is simulated by using Equation (3).

$$
T_{\text {out }}(t+\Delta t)=\frac{E(t)}{m_{a} \times C_{p, a}}+T_{a m b}(t)
$$

Table 2 below shows the values of constants used in the modelling of solar collector.

Table 2. Values of constants used in the modelling of solar collector.

\begin{tabular}{ccccc}
\hline S. No. & Symbol & Explanation & Value & Unit \\
\hline 1 & $m_{a}$ & Air mass flow rate & 0.037 & $\mathrm{~kg} / \mathrm{s}$ \\
2 & $A_{c}$ & Area of collector & 7 & $\mathrm{~m}^{2}$ \\
3 & $C_{p, a}$ & Air specific heat & 1000 & $\mathrm{~J} / \mathrm{kgK}$ \\
4 & $\eta_{o p t}$ & Collector optical efficiency & 0.566 & - \\
5 & $k_{1}$ & Heat transfer coefficients & 0.94 & $\mathrm{~W} / \mathrm{m}^{2} \mathrm{~K}$ \\
6 & $k_{2}$ & Heat transfer coefficients & 0.0071 & $\mathrm{~W} / \mathrm{m}^{2} \mathrm{~K}^{2}$ \\
\hline
\end{tabular}

\subsection{The Reactor}

The reactor is the most important component of the whole system, which holds the solid desiccant material in the presence of passing air through it. The reactor is an openatmospheric bed type reactor that operates at atmospheric pressure. The hydration and dehydration reactions occur as the air passes through the reactor and the temperature of passing air keeps changing, which alters the heat transfer rate as a function of position inside the reactor. The desiccant material's temperature is not uniform inside the reactor as the material does not have enough heat transfer within itself. Every portion of the reactor material has its temperature and its heat transfer rate. The desiccant material absorbs moisture from the passing air while hydrating and releases moisture to the air while dehydrating. This requires the mass transfer of moisture to or from the air as well. The heat of the reaction is released during hydration and absorbed during dehydration. $\mathrm{MgCl}_{2}$ is the thermochemical heat storage material used in this study. The hydration and dehydration reactions are summarised in Table 3 [29]. These reactions are typical atmospheric conditions with partial water pressure of around $13.6 \mathrm{mbar}$ in the air. 
Table 3. Magnesium chloride dehydration reaction properties.

\begin{tabular}{ccc}
\hline Reaction & $\begin{array}{c}\Delta \mathbf{H} \\
(\mathbf{k J} / \mathbf{m o l} \text { of Salt })\end{array}$ & $\begin{array}{c}\text { Reaction } \\
\text { Temperature }\left({ }^{\circ} \mathbf{C}\right)\end{array}$ \\
\hline $\mathrm{MgCl}_{2} \cdot 6 \mathrm{H}_{2} \mathrm{O}(\mathrm{s}) \rightarrow \mathrm{MgCl}_{2} \cdot 4 \mathrm{H}_{2} \mathrm{O}(\mathrm{s})+2 \mathrm{H}_{2} \mathrm{O}(\mathrm{g})$ & 116.4 & 50 \\
$\mathrm{MgCl}_{2} \cdot 4 \mathrm{H}_{2} \mathrm{O}(\mathrm{s}) \rightarrow \mathrm{MgCl}_{2} \cdot 2 \mathrm{H}_{2} \mathrm{O}(\mathrm{s})+2 \mathrm{H}_{2} \mathrm{O}(\mathrm{g})$ & 135.6 & 80 \\
$\mathrm{MgCl}_{2} \cdot 2 \mathrm{H}_{2} \mathrm{O}(\mathrm{s}) \rightarrow \mathrm{MgCl}_{2} \cdot \mathrm{H}_{2} \mathrm{O}(\mathrm{s})+\mathrm{H}_{2} \mathrm{O}(\mathrm{g})$ & 71.3 & 115 \\
$\mathrm{MgCl}_{2} \cdot \mathrm{H}_{2} \mathrm{O}(\mathrm{s}) \rightarrow \mathrm{MgOHCl}^{\mathrm{HCH}} \mathrm{HCl}(\mathrm{g})$ & 83.5 & 140 \\
\hline
\end{tabular}

The heat transfer model between the air and solid desiccant material particles is taken as one-dimensional. Figure 7 shows the conceptual variation of bed temperature for the hydration reaction.

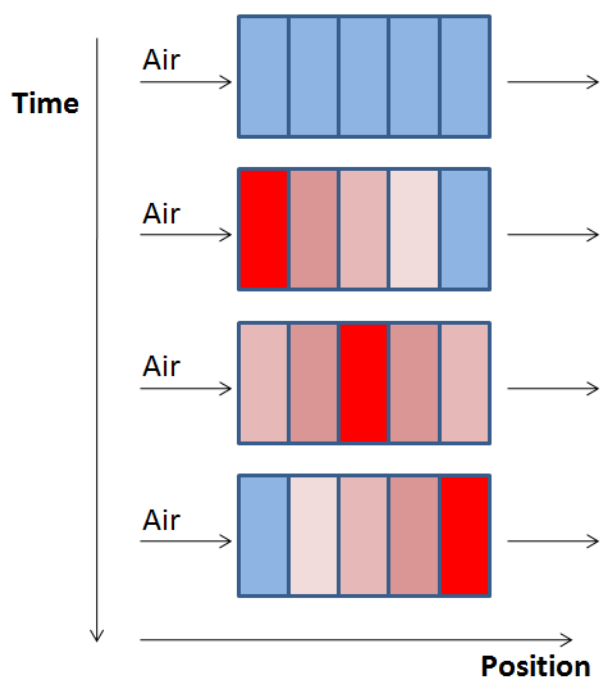

Figure 7. Travel of reaction front inside the reactor as a function of time during hydration.

During dehydration, high-temperature air enters the rector and increases the temperature of the bed segments. When a segment's temperature reaches the dehydration temperature, the temperature stops increasing, and the heat energy is absorbed to break the chemical bonds of the water and desiccant material molecules. When the moisture is completely removed from the segment, the temperature of the bed segment starts increasing. The heat transfer between air and small particles is modelled by using the Schaumann method [30]. If $T_{a}$ is the temperature of air and $T_{b}$ is the temperature of the reactor bed, then the heat balance can be described by the following Equation (4).

$$
\epsilon \rho_{a} c_{p, a} \frac{\partial T_{a}}{\partial t}=-\frac{m_{a} c_{p, a}}{A_{\text {reactor }}} \frac{\partial T_{a}}{\partial x}+h_{v}\left(T_{b}-T_{a}\right)
$$

where $\epsilon$ is the porosity and $\rho_{\mathrm{a}}$ is the density of air.

The left-hand side of the equation gives the rate of change of energy of air with respect to the time per unit volume of the air inside the reactor. This rate of change of energy is equal to the net heat entering the air. The second term on the right-hand side is the heat entering the air from the bed, and $h_{v}$ is the volumetric heat transfer coefficient between air and reactor bed. The first term is the heat getting out of the air because of its flow rate. The ma is the mass flow rate of air, and $A_{\text {reactor }}$ is the cross-sectional area of the reactor, and $x$ is the axial position inside the reactor. The reactor bed is divided into small segments with the assumption that the temperature of one segment is constant to facilitate solving the energy balance equation. For that, the size of one segment should be small enough that the temperature difference across the segment is negligible. The first step is to check a reasonable value of the number of segments $\mathrm{N}$ and the time interval $\Delta \mathrm{t}$. After running 
various simulations, the $\mathrm{N}$ value is chosen to be 10 and $\Delta \mathrm{t}$ of $30 \mathrm{~s}$ is selected. During the hydration process, the reaction rate depends upon the state of charge (SOC) of the reactor desiccant material. The SOC of the desiccant material varies between 0 and 1 ( 1 for fully dry). For the higher value of SOC, the reaction takes place quickly, and almost all the moisture is absorbed. This concept is implemented in the model by introducing a kinetic parameter $k_{p}$. It can be estimated by Equation (5).

$$
k_{p}(t, x)=1-\exp (-A \times \operatorname{SOC}(t, x))
$$

$A$ is the amplification factor, and increasing the value of $A$ would result in a steep decrease of the kinetic parameter. The reaction rate depends on not only the SOC but also the water vapour mass flow rate. The reaction rate $(r)$ is calculated by Equation (6):

$$
r(t, x)=k_{p}(t, x) \times M_{\text {vap }}(t, x)
$$

Here, $M_{\text {vap }}$ is the molar vapour flow rate in mol/s, which is also the unit of $r$. The dehydration process modelling assumes that the reaction is swift and is governed by the temperature difference between the air and the bed. When the bed's temperature reaches the material's dehydration temperature, the temperature of the bed stops increasing, and the heat absorbed is utilised to break the chemical bonds to release water molecules. The dehydration starts with a SOC value of 0 , and the SOC value increases as the water is released. The SOC of a segment is calculated by the amount of energy that is absorbed by the material of the segment $Q_{\text {stored }}$, relative to energy required by the segment to release all the water molecules $Q_{\max }$. SOC is calculated by Equation (7).

$$
\operatorname{SOC}(t, x)=\frac{Q_{\text {stored }}(t, x)}{Q_{\max }}
$$

The SOC value is calculated for every bed segment and each step to simulate the transient behaviour.

\subsection{The Building}

The building for which the system has been designed is a bedroom for accommodating two people. The room has a volume of $36 \mathrm{~m}^{3}(4 \mathrm{~m} \times 3 \mathrm{~m} \times 3 \mathrm{~m})$ with a floor area of $12 \mathrm{~m}^{2}$. For thermal modelling, the room's infiltration is taken to be 1 air change per hour $(\mathrm{ACH})$, which is $0.0123 \mathrm{~kg} / \mathrm{s}$ for a normal air density of $1.23 \mathrm{~kg} / \mathrm{m}^{3}$. A total intake of $4 \mathrm{ACH}$ is required to maintain indoor air quality. The rest of the $3 \mathrm{ACH}$ is provided by the ventilation flow rate, which becomes $0.0369 \mathrm{~kg} / \mathrm{s}$. This is the mass flow of air provided by the designed DEC system, and the same amount of air is removed from the room. The indoor design temperature of the room is taken to be $26^{\circ} \mathrm{C}$. Figure 8 shows the heat streams entering and leaving the room. The solar gains are not considered because the cooling system has been designed to operate only at night. Table 4 shows the values of different parameters used for building's cooling demand modelling.

Table 4. Values of different parameters for thermal modelling of a building.

\begin{tabular}{cccccc}
\hline Symbol & Value & Unit & Symbol & Value & Unit \\
\hline $\mathrm{V}_{\text {room }}$ & 36 & $\mathrm{~m}^{3}$ & $\mathrm{~T}_{\text {room }}$ & 26 & ${ }^{\circ} \mathrm{C}$ \\
$\mathrm{A}_{\text {floor }}$ & 12 & $\mathrm{~m}^{2}$ & $\mathrm{~N}$ & 2 & - \\
Infiltration & 1 & $\mathrm{ACH}$ & $\mathrm{Q}_{\mathrm{pp}}$ & 100 & $\mathrm{~W}$ \\
$\mathrm{~m}_{\text {inf }}$ & 0.0123 & $\mathrm{~kg} / \mathrm{s}$ & $\mathrm{C}_{\mathrm{p}, \mathrm{a}}$ & 1000 & $\mathrm{~J} / \mathrm{kg} \mathrm{K}$ \\
$\mathrm{P}_{\mathrm{a}}$ & 1.23 & $\mathrm{~kg} / \mathrm{m}^{3}$ & $\mathrm{Q}_{\text {el. Appl. }}$ & 150 & $\mathrm{~W}$ \\
Ventilation & 3 & $\mathrm{ACH}$ & $\mathrm{U}_{\text {room }}$ & 0.35 & $\mathrm{~W} / \mathrm{m}^{2} \mathrm{~K}$ \\
$\mathrm{~m}_{\mathrm{a}}$ & 0.0369 & $\mathrm{~kg} / \mathrm{s}$ & $\mathrm{A}_{\text {room }}$ & 54 & $\mathrm{~m}^{2}$ \\
\hline
\end{tabular}




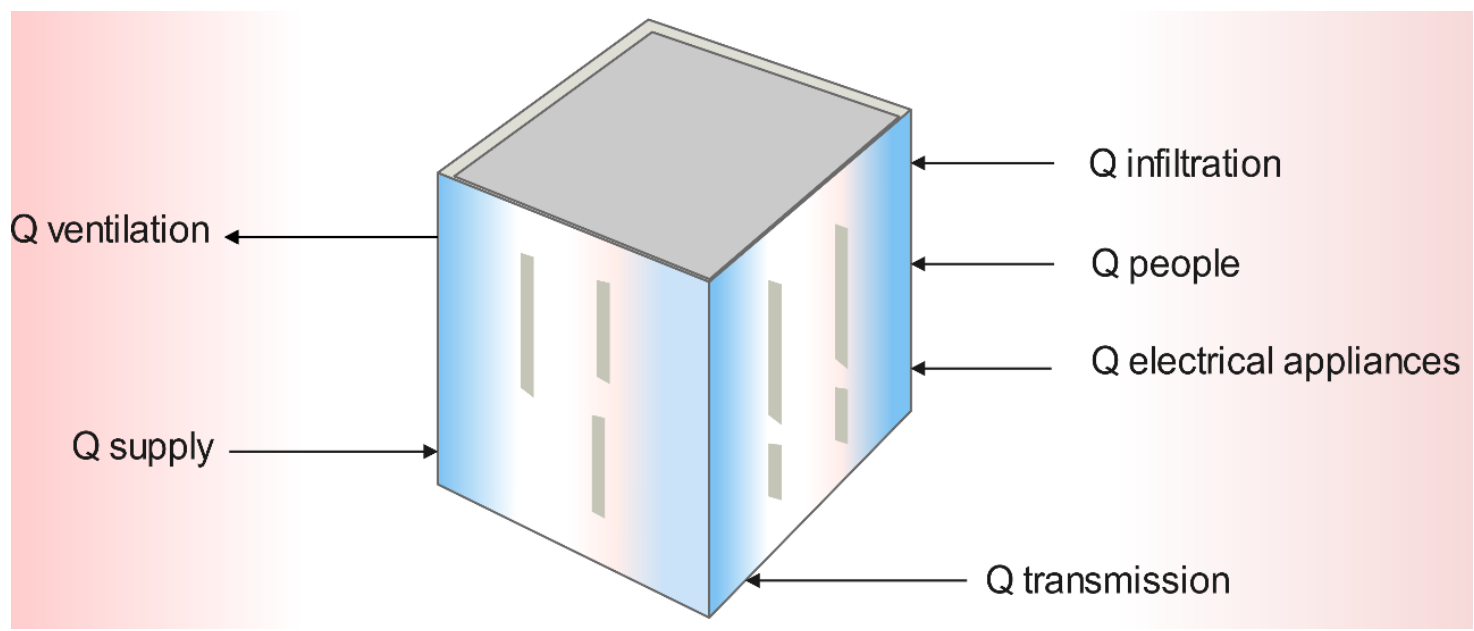

Figure 8. Heat balance of the building with all the entering and leaving streams.

The heat exchangers used in the system have been modelled by the effectiveness method. The effectiveness of heat exchangers is the actual heat transfer divided by maximum possible heat transfer. For the psychrometric calculations, the following Equations (8)-(10) are used to calculate the absolute humidity $\left(X_{w}\right)$ and the enthalpy of the air $\left(h_{\text {air }}\right)$.

$$
\begin{aligned}
X_{w}= & \frac{M_{v}}{M_{a}} \times \frac{P_{v}}{P_{t o t}-P_{v}}=0.622 \times \frac{P_{v}}{P_{t o t}-P_{v}} \\
h_{a i r} & =T C_{p, a}+X_{w}\left(r+C_{p, v} T\right) \\
h_{\text {air }} & =T+X_{w}(2500+1.86 T)
\end{aligned}
$$

where $M_{v}$ is the molar mass of water $(18 \mathrm{~kg} / \mathrm{kmol}), M_{a}$ is the molar mass of air $(29 \mathrm{~kg} / \mathrm{kmol})$, and $P_{\text {tot }}$ is the total pressure of the humid air, $r$ is the latent heat of vaporisation of water $\left(2500 \mathrm{~kJ} / \mathrm{kg}\right.$ at $\left.0{ }^{\circ} \mathrm{C}\right)$, and $C_{p, v}$ is the specific heat of water vapour $(1.86 \mathrm{~kJ} / \mathrm{kg} . \mathrm{K})$.

\section{Results and Discussion}

For system simulations, the individual component models are integrated to simulate the whole system's operation. The reactor size is optimised by reducing the hydration time of the whole reactor. The solar collector model is integrated with the reactor's dehydration model. The cooling provided by the whole system is simulated, and the solar fraction is calculated. Figure 9 shows the modelling results for a $1 \mathrm{~d}$ (1st July). 


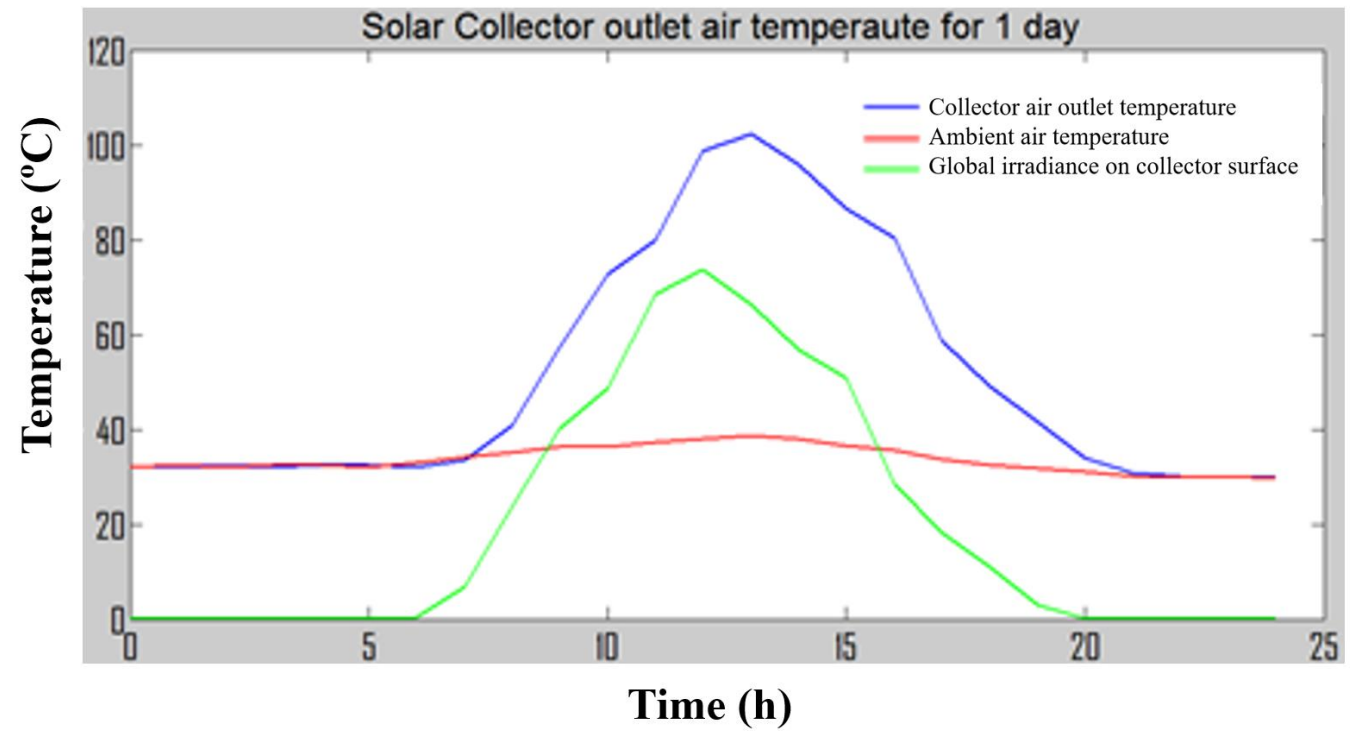

Figure 9. Solar collector simulation of one day, variation of air outlet temperature $\left(T_{\text {out }}\right), T_{a m b}$, and $G$ with time.

$T_{a m b}$ and $G$ are taken from the weather data. The values of $T_{\text {out }}$ are going above the $80{ }^{\circ} \mathrm{C}$ mark for around $8 \mathrm{~h}$. The $\mathrm{T}_{\text {out }}$ is following the $\mathrm{G}$ in shape, which is in accordance with equation 3.5. It should be noted that $T_{\text {out }}$ is lagging the $G$ in time. This is because $\mathrm{T}_{\text {out }}$ is calculated by using the value of $\mathrm{E}$ from the previous time step. The mass flow rate $\left(\mathrm{m}_{\mathrm{a}}\right)$ is the same, which will be used for hydration of desiccant and obtained by the room's ventilation requirements to be cooled. The mass flow can be different as well because charging and discharging is done separately. The constants $\eta_{\mathrm{opt}}, \mathrm{k}_{1}$, and $\mathrm{k}_{2}$ are the collector's construction properties and define the amount of energy that the collector can absorb according to Equation (1). The simulation results for variation of $\mathrm{T}_{\text {out }}$ profiles with the area of the collector is shown in Figure 10.

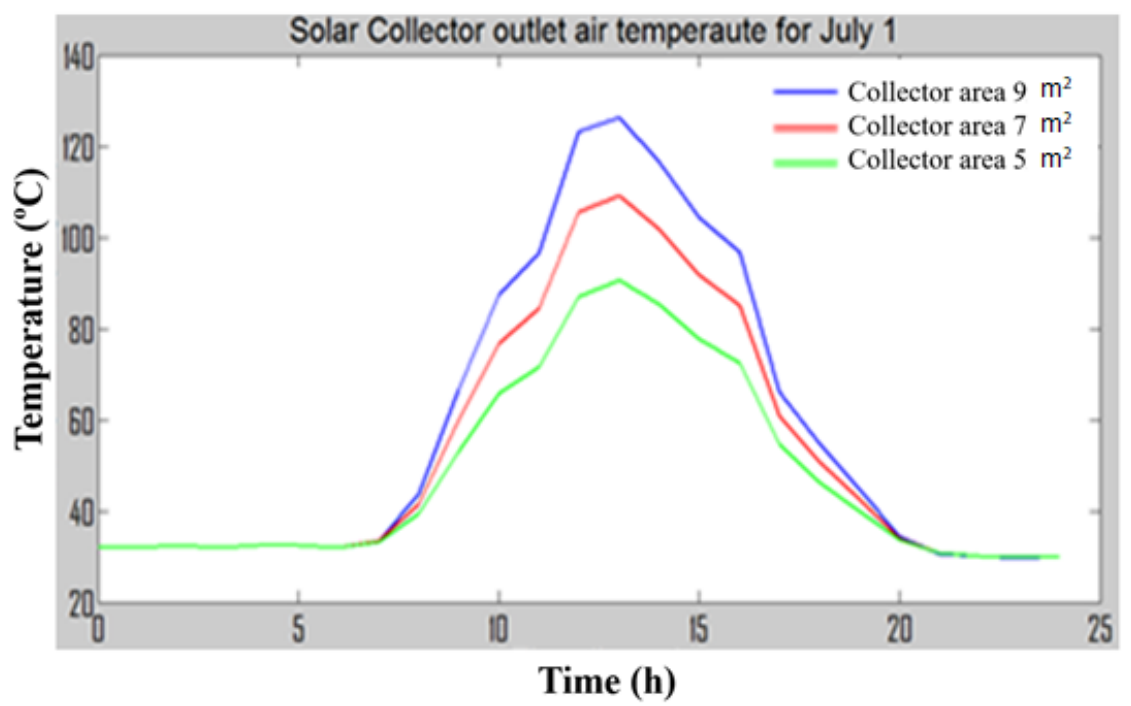

Figure 10. The effect of collector area on the collector outlet temperature.

By increasing the collector area from $5 \mathrm{~m}^{2}$ to $9 \mathrm{~m}^{2}$, the maximum temperature reached by the air changes from around $90-130{ }^{\circ} \mathrm{C}$. A more extensive collector area means higher initial cost and more extended payback time. Figure 11 shows the modelling results of evaporator 1 . 


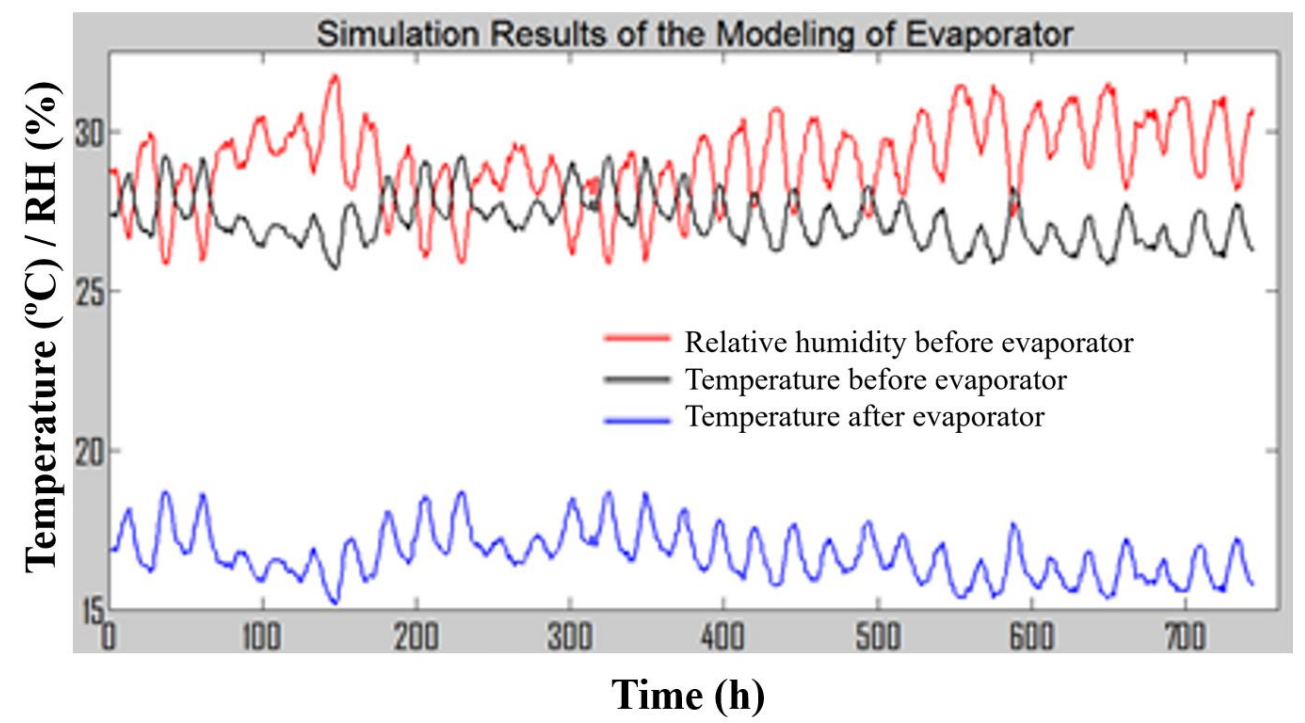

Figure 11. Simulation of temperature drop achieved by evaporator-1 for the whole month.

The evaporator model takes the values of temperature and humidity of the entering air. The evaporator is modelled to increases the relative humidity of the air to $90 \%$. The temperature drops because evaporation is calculated by using the psychrometric modelling equations. A temperature drop of around $10{ }^{\circ} \mathrm{C}$ is achieved in the evaporator by increasing the relative humidity by $60 \%$. Figure 12 shows the simulation result of the hydration process of a reactor with reduced size.

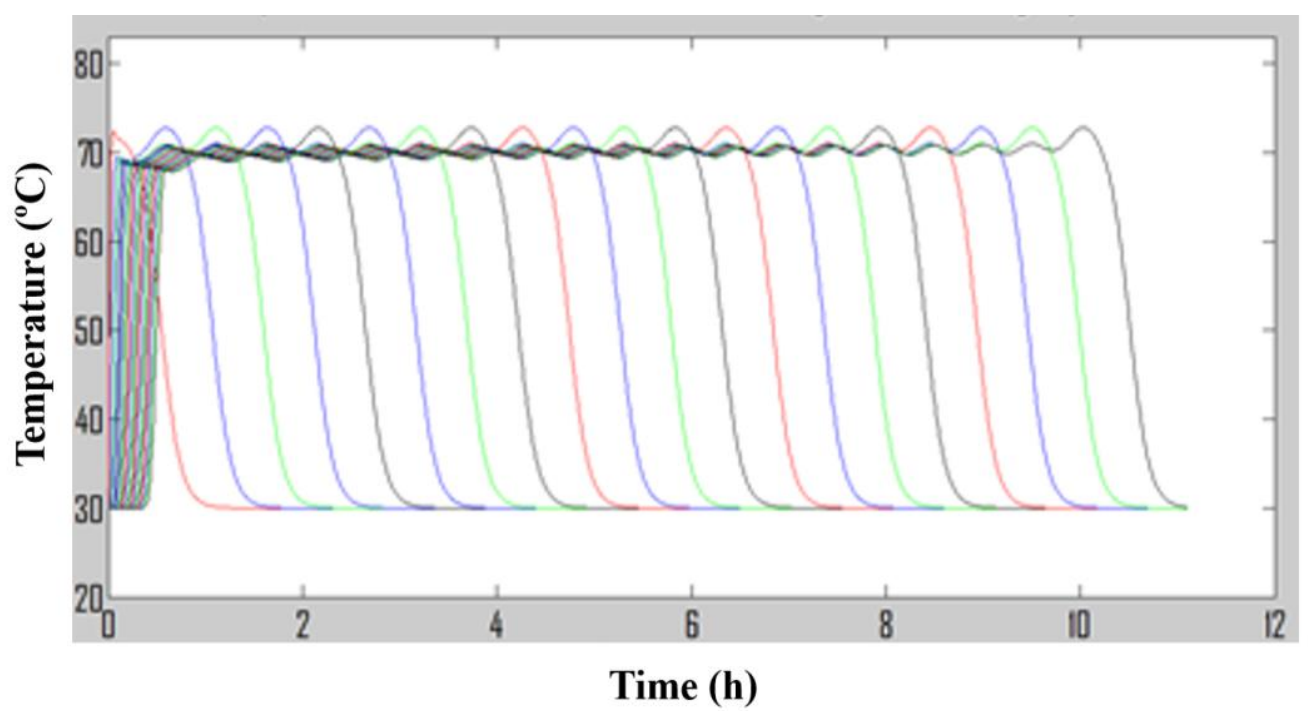

Figure 12. Simulation of hydration of reactor with reduced size.

Figure 12 shows that the time required for the reactor's total hydration has come down to around $11 \mathrm{~h}$. An air mass flow rate of $0.0369 \mathrm{~kg} / \mathrm{s}$ was used in this simulation. The size was achieved by reducing the length of the reactor to $0.55 \mathrm{~m}$ and the diameter of the reactor to $0.65 \mathrm{~m}$. The porosity of the reactor was increased to 0.8 . This resulted in a reduction of the mass of the desiccant to a value of $57 \mathrm{~kg}$, which is a reduction of about $72 \%$ in the mass. Figure 13 shows the integrated system's simulation results when the reactor is taking air from the ambient. 


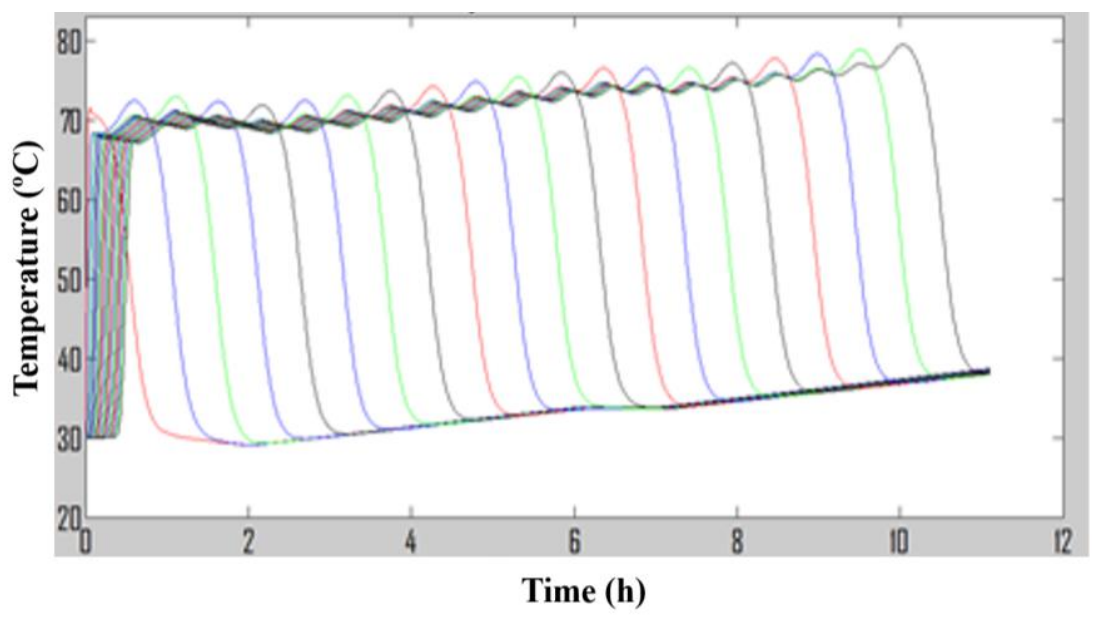

Figure 13. Simulation of the hydration process of an integrated reactor with an ambient air intake in the night starting at 10:00 PM of 1st July.

The reactor segments are hydrated when the ambient air passes through the reactor. When the hydration reaction completes a segment, its temperature comes down to the intake air temperature, which is varying continuously. The complete hydration of the reactor takes around $11 \mathrm{~h}$. It means the system can provide cooling for up to $11 \mathrm{~h}$. Figure 14 shows the simulation results of T4, T6, and T7 (referring to Figure 5).

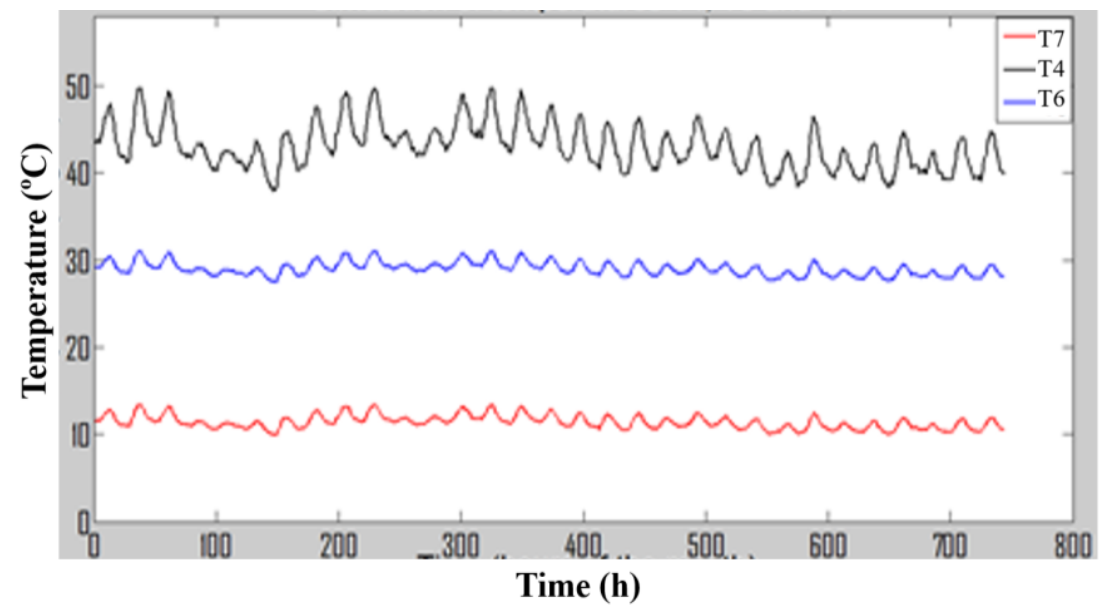

Figure 14. Simulation of temperatures of supply air at different stages of the system (T7 is room supply temperature after evaporator 1, T6 is temperature after HE 2, and T4 is temperature after HE 1).

Heat exchanger 1 reduces the temperature of dry air coming out of the reactor and brings it down to T4. Heat exchanger 2 reduces the temperature from T4 to T6. Evaporator 1 brings the temperature of air down to T7 from T6 by evaporation. This simulation assumes a constant supply of dry air from the reactor by repeating the cycle. The system operates only at night, which corresponds to the lower values of these graphs. Figure 15 represents the net cooling demand (cooling demand-cooling supplied) for the room. 


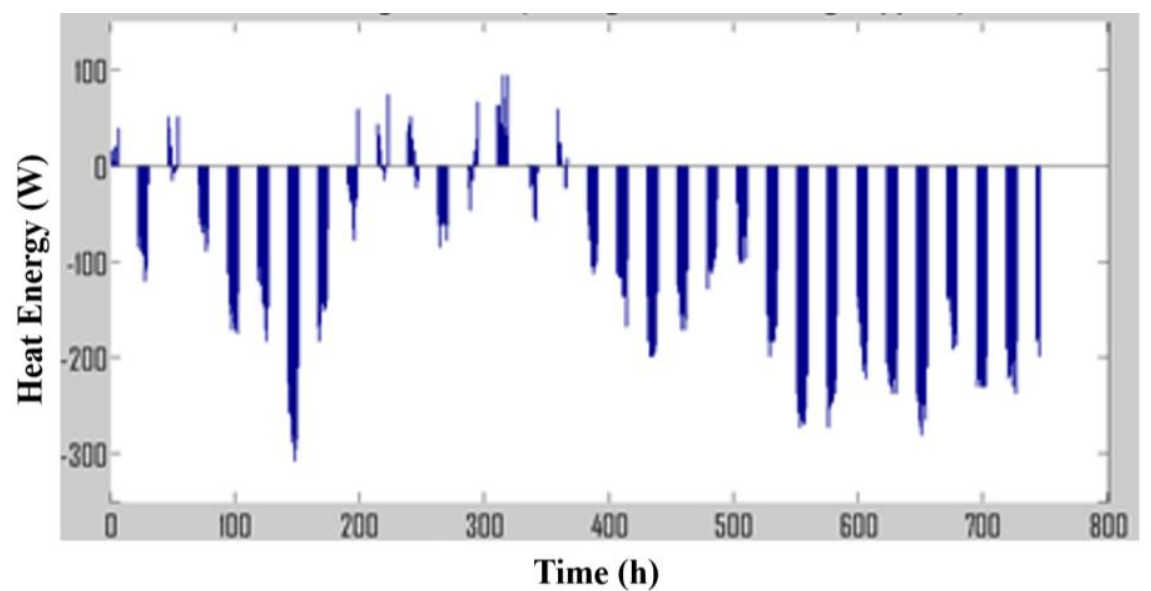

Figure 15. Simulation of net cooling demand of the room on the nights of July.

The positive values indicate that the cooling demand is more than the cooling supplied, and the DEC system cannot meet the cooling demand. The auxiliary cooling system will provide this excess cooling. The negative values are for the colder nights when the DEC system provides more cooling (removing more heat) than required by the room. Ideally, the net cooling demand of the room should always be zero. This is achieved by turning the cooling system off after regular intervals or reducing the mass flow rate of supply air by reducing the fan's speed. If all the positive values of the net cooling demand obtained, it gives the total cooling provided by the auxiliary system for July. This value obtained to be $1.462 \mathrm{kWh}$. The total cooling demand of the room for the nighttime found to be $124.32 \mathrm{kWh}$. This gives the solar fraction of $98.8 \%$. It means that with these dimensions of the system, the system can meet $98.8 \%$ of the room's cooling demand in July. Figure 16 shows the simulation result for net cooling demand.

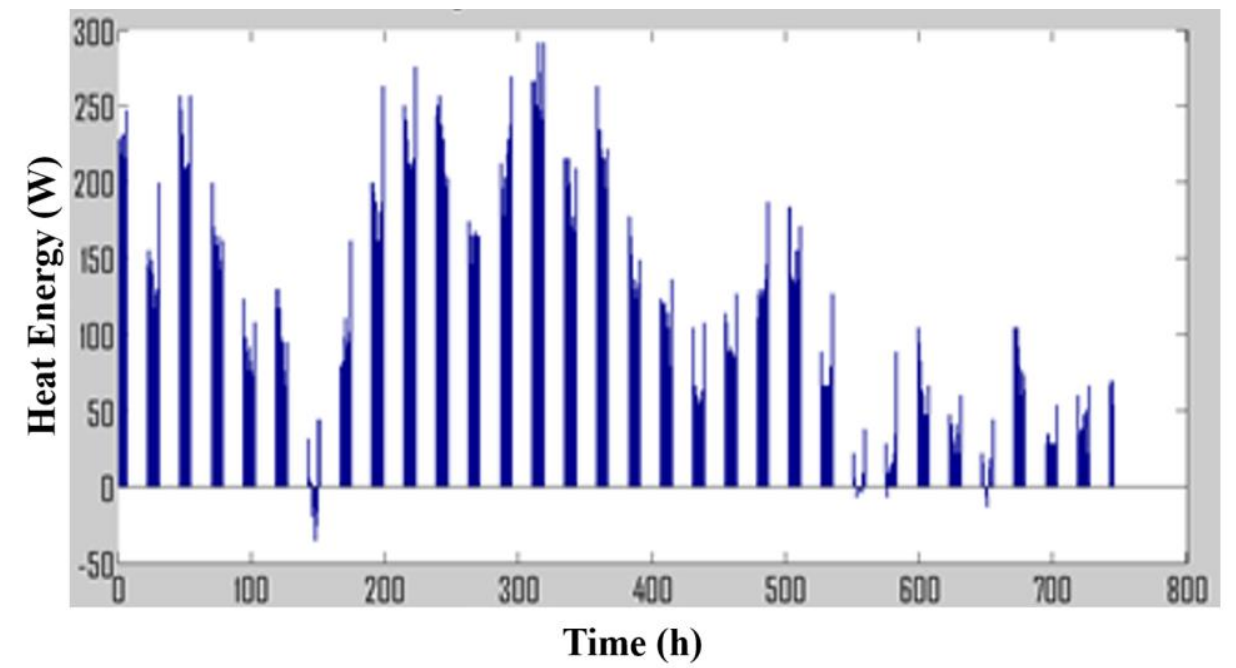

Figure 16. Simulation of net cooling demand of the room with reduced $U$ value of the room in the nights of July.

In this case, the cooling demand of the room drops to $217.4 \mathrm{kWh}$. The auxiliary cooling needed by the room also reduces to $34.3 \mathrm{kWh}$. This gives the solar fraction of $84.2 \%$. By decreasing the room's U value by $0.1 \mathrm{~W} / \mathrm{m}^{2} \mathrm{~K}$, the solar fraction is increased by $1.8 \%$. Similarly, the effect of changing other parameters can be studied by varying their values in the model and running the simulation for various operating conditions. For the basic design, the system shows quite positive results. The affirmative results provide considerable encouragement for refining the system further by going into more 
details of different simplifications made in the modelling and working towards developing technology. A following important effect is an option for reducing the environmental impact [31] quantified by, e.g., GHG footprints [32].

\section{Conclusions}

A solar DEC system has been designed and analysed using numerical simulations. The system has been uniquely designed in such a way that the desiccant material $\left(\mathrm{MgCl}_{2} \cdot 6 \mathrm{H}_{2} \mathrm{O}\right)$ serves two purposes simultaneously; it works as a desiccant and as a daily solar heat storage medium. The system has been designed to produce solar cooling for a small building situated in the subtropical city of Lahore, Pakistan. The desiccant holding reactor has been transiently modelled numerically in such a way that its total length is divided into 20 segments, and an appropriate time step of $30 \mathrm{~s}$ has been selected. The reactor's initial design and simulation gave a total hydration time of $29 \mathrm{~h}$ for a mass of desiccant of $201 \mathrm{~kg}$. For meeting the cooling demand of the selected building (system integration), this time is reduced to $11 \mathrm{~h}$ for $57 \mathrm{~kg}$ of desiccant material. The solar collector is modelled numerically and is integrated with the dehydration model of the reactor. It is found that the $7 \mathrm{~m}^{2}$ collector dehydrated the desiccant material in approximately $5 \mathrm{~h}$. The integration of the reactor's hydration model with models of heat exchangers and evaporators showed that the designed solar DEC system could meet $98.8 \%$ (solar fraction) of the building's cooling demand for the whole month of July, providing $122.86 \mathrm{kWh}$ of cooling. The system provided a solar fraction of $70.4 \%$ when the number of people in the building and electrical appliances' heat is doubled. However, the system's cooling in the second case increased to $156.17 \mathrm{kWh}$ due to lesser cooling losses. The cooling output of the system increased with the increasing heat exchanger effectiveness. When the heat exchangers' effectiveness increased from 0.7 to 0.8 , solar fraction increased from $70.4 \%$ to $82.44 \%$. It shows that investing in advanced heat exchangers is desirable for such a system. By decreasing the $\mathrm{U}$ value of the room from 0.35 to $0.25 \mathrm{~W} / \mathrm{m}^{2} \mathrm{~K}$, the solar fraction increased from $82.44 \%$ to $84.2 \%$. The results obtained by using the weather data of the city of Lahore showed strong feasibility of using solar driven DEC in subtropical climate (higher latent cooling loads), where enough solar energy is available during the day. The energy can be stored and used during the night for air conditioning.

Author Contributions: Conceptualisation, methodology, visualisation, writing-original draft F.R. and M.A.Q. supervision, J.J.K. and M.L.; validation, M.A.; data curation, M.R.A.; formal analysis, M.U.; investigation, M.I.; writing—original draft, F.R., M.A.Q. and A.B.; writing—review and editing, A.B. and J.J.K.; visualisation, A.B.; project administration, J.J.K.; funding acquisition, J.J.K. All authors have read and agreed to the published version of the manuscript.

Funding: This research received no external funding.

Institutional Review Board Statement: Not applicable.

Informed Consent Statement: Not applicable.

Acknowledgments: The authors would like to acknowledge the support from the project "Sustainable Process Integration Laboratory-SPIL" funded by EU CZ Operational Programme Research and Development, Education, Priority1: Strengthening capacity for quality research (Grant No. CZ.02.1.01/0.0/0.0/15_003/000045).

Conflicts of Interest: The authors declare no conflict of interest.

\section{References}

1. Eicker, U. Low Energy Cooling for Sustainable Buildings; John Wiley and Sons: Chichester, UK, 2009.

2. Mao, N.; Pan, D.; Li, Z.; Xu, Y.; Song, M.; Deng, S. A numerical study on influences of building envelope heat gain on operating performances of a bed-based task/ambient air conditioning (TAC) system in energy saving and thermal comfort. Appl. Energy 2017, 192, 213-221. [CrossRef]

3. Awan, M.R.; Riaz, F.; Nabi, Z. Analysis of conditions favourable for small vertical axis wind turbines between building passages in urban areas of Sweden. Int. J. Sustain. Energy 2017, 36, 450-461. [CrossRef] 
4. Global Demand for Air-Conditioning to Triple by 2050: Report the Straits Times. 2018. Available online: https://www.straitstimes. com/business/global-demand-for-air-conditioning-to-triple-by-2050-report (accessed on 8 March 2021).

5. Hamzaoui, M.; Nesreddine, H.; Aidoun, Z.; Balistrou, M. Experimental study of a low grade heat driven ejector cooling system using the working fluid R245fa. Int. J. Refrig. 2018, 86, 388-400. [CrossRef]

6. Zare, V.; Palideh, V. Employing thermoelectric generator for power generation enhancement in a Kalina cycle driven by low-grade geothermal energy. Appl. Therm. Eng. 2018, 130, 418-428. [CrossRef]

7. Lawal, D.U.; Qasem, N.A.A. Humidification-dehumidification desalination systems driven by thermal-based renewable and low-grade energy sources: A critical review. Renew. Sustain. Energ. Rev. 2020, 125, 109817. [CrossRef]

8. Muhammad Ashraf, W.; Moeen Uddin, G.; Muhammad Arafat, S.; Afghan, S.; Hassan Kamal, A.; Asim, M.; Haider Khan, M.; Waqas Rafique, M.; Naumann, U.; Niazi, S.G.; et al. Optimisation of a 660 MWe supercritical power plant performance-a case of industry 4.0 in the data-driven operational management part 1. Thermal efficiency. Energies 2020, 13, 5592. [CrossRef]

9. Riaz, F.; Lee, P.S.; Chou, S.K.; Ranjan, R.; Tay, C.S.; Soe, T. Analysis of low-grade waste heat driven systems for cooling and power for tropical climate. Energy Procedia 2017, 143, 389-395. [CrossRef]

10. Riaz, F.; Tan, K.H.; Farooq, M.; Imran, M.; Lee, P.S. Energy analysis of a novel ejector-compressor cooling cycle driven by electricity and heat (waste heat or solar energy). Sustainability 2020, 12, 8178. [CrossRef]

11. Chen, Q.; Alrowais, R.; Burhan, M.; Ybyraiymkul, D.; Shahzad, M.W.; Li, Y.; Ng, K.C. A self-sustainable solar desalination system using direct spray technology. Energy 2020, 205, 118037. [CrossRef]

12. Kanoğlu, M.; Özdinç Çarpınlığlu, M.; Yıldırım, M. Energy and exergy analyses of an experimental open-cycle desiccant cooling system. Appl. Therm. Eng. 2004, 24, 919-932. [CrossRef]

13. Riaz, F.; Lee, P.S.; Chou, S.K. Thermal modelling and optimisation of low-grade waste heat driven ejector refrigeration system incorporating a direct ejector model. Appl. Therm. Eng. 2020, 167, 114710. [CrossRef]

14. Rady, M.A.; Huzayyin, A.S.; Arquis, E.; Monneyron, P.; Lebot, C.; Palomo, E. Study of heat and mass transfer in a dehumid-ifying desiccant bed with macro-encapsulated phase change materials. Renew. Energy 2009, 34, 718-726. [CrossRef]

15. Paksoy, H.O.; Andersson, O.; Abaci, S.; Evliya, H.; Turgut, B. Heating and cooling of a hospital using solar energy coupled with seasonal thermal energy storage in an aquifer. Renew. Energy 2000, 19, 117-122. [CrossRef]

16. Narayanan, R.; Halawa, E.; Jain, S. Performance characteristics of solid-desiccant evaporative cooling systems. Energies 2018, 11, 2574. [CrossRef]

17. Henning, H.-M. Solar assisted air conditioning of buildings-An overview. Appl. Therm. Eng. 2007, 27, 1734-1749. [CrossRef]

18. Mazzei, P.; Minichiello, F.; Palma, D. HVAC dehumidification systems for thermal comfort: A critical review. Appl. Therm. Eng. 2005, 25, 677-707. [CrossRef]

19. Fatouh, M.; Abou-Ziyan, H.; Mahmoud, O.; Abd El-Raheim, D. Experimental analysis of hybrid and conventional air conditioning systems working in hot-humid climate. Appl. Therm. Eng. 2017, 118, 570-584. [CrossRef]

20. Finocchiaro, P.; Beccali, M.; Cellura, M.; Guarino, F.; Longo, S. Life cycle assessment of a compact desiccant evaporative cooling system: The case study of the "Freescoo". Sol. Energy Mater. Sol. Cells 2016, 156, 83-91. [CrossRef]

21. Ham, S.-W.; Lee, S.-J.; Jeong, J.-W. Operating energy savings in a liquid desiccant and dew point evaporative cooling-assisted 100\% outdoor air system. Energy Build. 2016, 116, 535-552. [CrossRef]

22. Ge, T.S.; Dai, Y.J.; Wang, R.Z.; Li, Y. Feasible study of a self-cooled solid desiccant cooling system based on desiccant coated heat exchanger. Appl. Therm. Eng. 2013, 58, 281-290. [CrossRef]

23. La, D.; Dai, Y.J.; Li, Y.; Tang, Z.Y.; Ge, T.S.; Wang, R.Z. An experimental investigation on the integration of two-stage dehumidification and regenerative evaporative cooling. Appl. Energy 2013, 102, 1218-1228. [CrossRef]

24. El Hourani, M.; Ghali, K.; Ghaddar, N. Effective desiccant dehumidification system with two-stage evaporative cooling for hot and humid climates. Energy Build. 2014, 68, 329-338. [CrossRef]

25. Beccali, M.; Finocchiaro, P.; Nocke, B. Energy performance evaluation of a demo solar desiccant cooling system with heat recovery for the regeneration of the adsorption material. Renew. Energy 2012, 44, 40-52. [CrossRef]

26. Rafique, M.M.; Gandhidasan, P.; Rehman, S.; Alhems, L.M. Performance analysis of a desiccant evaporative cooling system under hot and humid conditions. Environ. Prog. Sustain. Energy 2016, 35, 1476-1484. [CrossRef]

27. Urieli, I. (2010, June), Engineering Thermodynamics A Graphical Approach Paper presented at 2010 Annual Conference \& Exposition, Louisville, Kentucky. 10.18260/1-2-15662. Available online: https:/ / peer.asee.org/engineering-thermodynamics-agraphical-approach (accessed on 26 February 2021).

28. C603 Solar Collector Factsheet Thermomax Solamax 20-TDS 300. Available online: http://www.spf.ch/fileadmin/daten/ reportInterface/kollektoren/factsheets/scf600en.pdf (accessed on 26 February 2021).

29. Zondag, H.; Kikkert, B.; Smeding, S.; Boer, R.D.; Bakker, M. Prototype thermochemical heat storage with open reactor system. Appl. Energy 2013, 109, 360-365. [CrossRef]

30. Schumann, T.E.W. Heat transfer: A liquid flowing through a porous prism. J. Franklin Inst. 1929, 208, 405-416. [CrossRef]

31. Klemeš, J.J. (Ed.) Assessing and Measuring Environmental Impact and Sustainability; Butterworth-Heinemann/Elsevier: Oxford, UK, 2015; 559p, ISBN 978-0-12-799968-5. [CrossRef]

32. Klemeš, J.J.; Van Fan, Y.; Jiang, P. The energy and environmental footprints of COVID-19 fighting measures-PPE, disinfection, supply chains. Energy 2020, 211, 118701. [CrossRef] [PubMed] 